\title{
KOMMENTAR
}

\section{Armer Wohlfahrtsstaat?}

Stephan Lessenich

„Die Krise“, so groß und tief wie sie war (oder zu sein schien), ist mit einem Mal schon wieder Geschichte. Der bundesrepublikanische Wirtschaftsmotor brummt wieder, das Lob des deutschen (Export-)Unternehmertums füllt abermals - den chinesischen Industrieproduktionsbedarfen und Luxuskonsumgelüsten sei Dank - die Kommentare der Wirtschaftspresse. Die Krisen der kapitalistischen Wertschöpfung und -verwertung, so lernen wir derzeit zum x-ten Male, kommen und gehen. Was dabei nach allgemeinem Dafürhalten allerdings bleibt, ist die Krise des Wohlfahrtsstaats: jenes institutionellen Arrangements, das damit betraut ist, die allfälligen Akkumulationskrisen des Industriekapitalismus überbrücken und überwinden zu helfen - und die kurz- wie langfristigen sozialen Folgekosten des ökonomischen Krisenzyklus zu tragen. Wenn die Stimmungsbarometer und Wachstumsprognosen der Wirtschaftsforschungsinstitute schon längst wieder nach oben weisen, ist der Wohlfahrtsstaat noch lange damit beschäftigt, die Versorgungslücken und -nöte der Krisenverlierer zu verarbeiten - und, wenn er "modern“ und auf Zack ist, sich und seine Versorgungsklassen schon präventiv auf die nächste, bestimmt kommende Zeit des kollektiven (in Wahrheit aber selektiven) Gürtelengerschnallens vorzubereiten. Der Wohlfahrtsstaat ist permanent in der Krise, die Krise ist sein Schicksal: Er muss ihr nach- und vorsorgen, stürzt dabei selber von der einen in die nächste (Finanz-, Organisations-, Legitimations-)Krise, hat sich zu (und bei) allem Überfluss gar öffentlich als Krisenverursacher zu verantworten. Man könnte, aus einer systemischen Perspektive, die einen Sinn für seine strukturell ausweglos erscheinende Doppelkonstellation als Krisenmanager und Krisenherd hat, geradezu Mitleid entwickeln mit dem Wohlfahrtsstaat und dessen Steuerungspersonal - von Frau von der Leyen bis zum letzten ARGE-Fallmanager.

Doch wenn wir dem Wohlfahrtsstaat, seinen Funktionseliten und Funktionären schon Gefühle entgegenbringen wollen - was jedenfalls jenseits des Raums wissenschaftlicher Analyse durchaus nicht unangemessen erscheint -, dann dürfte Mitleid wohl weniger angebracht sein. Dass der Wohlfahrtsstaat grundsätzlich Gutes tut oder das Gute will oder zumindest stets danach strebt, das Gute zu erreichen, gehört zu den ebenso großen wie robusten, scheinbar unverwüstlichen gesellschaftlichen Alltagsmythen (und lässt „die Sozialpolitiker“ in Politik und Wissenschaft unvermeidlicherweise als wohlwollend-naive Gutmenschen erscheinen). Tatsächlich aber ist der Wohlfahrtsstaat kapitalistischer Gesellschaften ebenso sehr „Täter“ wie „Opfer“, und er kann - bei aller Bindung und Fesselung durch die Ökonomie dieser Gesellschaften - prinzipiell immer auch anders: statt Chancen-, Teilhabe- oder Verteilungsgerechtigkeit anzupeilen, kann er sie (oder wahlweise einen anderen hehren Wert) auch systematisch konterkarieren; statt die Lage der unteren Klassen zu heben, kann er deren Benachteiligung zementieren; statt den Geschundenen Pflege zu gewähren und den Beladenen Lasten abzunehmen, kann er sie zur Selbstsorge anhalten oder auch ganz einfach nur links liegen lassen.

Der moderne Wohlfahrtsstaat ist mitgefangen im großen gesellschaftlichen Krisengeschehen namens Kapitalismus, aber dabei auch ganz schön eigeninitiativ - und liegt damit durchaus im Trend der Zeit: Bildungsungleichheiten beklagen, sie zugleich aber fortschreiben und liberalinterventionistische Scheinlösungen (wie auf Wohlfahrtsmärkten einzulösende Gutscheine etwa) anbieten; Aktivität einfordern, aber die materiellen und immateriellen Grundlagen für deren Ausübung systematisch einschränken; Solidarität beschwören, aber faktisch gutbürgerliche Ressentiments und umgekehrten Sozialneid gegen die „überversorgten“ Staats-„,Klienten“ schüren; den gesellschaftlichen Zusammenhalt einklagen und dabei an bürgerschaftliches Engagement, Freiwilligenagenturen, soziale Pflichtjahre und ähnliche mittelschichtsfreundliche Harmonieszenarien denken, nicht aber an die ganz realen desintegrativen Effekte einer rasant wachsenden Einkommens- und einer geradezu absurden Vermögensungleichheit (und an mögliche Maßnahmen einer regulativen Gegensteuerung). Der Wohlfahrtsstaat kann durchaus Gesellschaft gestalten - sicher nicht immer, wie er will, aber doch immer so, dass die Gesellschaft es zu spüren bekommt. In seiner aktuellen Krise hat er, haben die in seinen Institutionen handelnden Personen sich dafür entschieden, die sozialen Verhältnisse hierzulande ungleicher werden zu lassen: Wer hat, dem soll gegeben werden. In diesem Wohlfahrtsstaat werden Bildungsarme auch in Zukunft massiv reduzierte Lebenschancen haben. Und die Gruppe der Bildungsarmen wird sich nach wie vor zu großen Teilen aus migrantischen Milieus rekrutieren. In diesem Wohlfahrtsstaat werden Langzeitarbeitslose auch in Zukunft unter administrativen Druck gesetzt werden, obwohl doch das gesellschaftliche Problem in einem eklatanten Unterangebot an ,guter Arbeit“ besteht. In diesem Wohlfahrtsstaat werden die Menschen in Zukunft selbst ihren späten Renteneintritt noch teuer bezahlen müssen, weil sie eben nur als „produktive“ Kräfte gesellschaftlich - und sozial-politisch - noch etwas zählen.

Was soll man dazu sagen - armer Wohlfahrtsstaat? Eher wohl: arme Wohlstandsgesellschaft, die sich einen solchen Wohlfahrtsstaat leistet.

\footnotetext{
Stephan Lessenich, Dr. habil., ist Professor für Vergleichende Gesellschafts- und Kulturanalyse an der Friedrich-Schiller-Universität Jena. Arbeitsschwerpunkte: Soziologie der Sozialpolitik, vergleichende Wohlfahrtsstaatsforschung, Soziologie des Alter(n)s. e-mail: stephan.lessenich@uni-jena.de
} 